\title{
Building Degree Profiles. The Tuning Approach
}

\author{
Julia González and Maria Yarosh
}

\begin{abstract}
The development of degree profiles is an important art which has become quite specialized in recent years. This article concentrates on the analysis of the importance of the role of degree profiles in the design of degrees and, as a consequence, in Higher Education in general. It analyses, particularly, the work of the Tuning Project and its main processes in relation to profile building. It also gathers together and systematizes the specific contribution of four main components which should be taken into consideration at the time of the creation of new qualifications: two of the components relate to the analysis of social and professional needs and the future trends in the area. Both of these elements provide the relevance which a degree profile should strive to attain. The third component, the reference to the meta-profile, provides a capacity for recognition throughout an entire region and also in relation to the global context. The last element in profile development takes into consideration the university where the programme is anchored, its mission and strengths.
\end{abstract}

Keywords: Degree; degree profile; reference points and meta-profiles; recognition; relevance; quality; social needs; levels; competences and learning outcomes; educational programme.

\section{Introduction and context}

The recent publication Communities of Learning: Networks and the Shaping of Intellectual Identity in Europe, 1100-1500 1 explores the fundamental insight that all new ideas are developed in the context of a community, whether academic, religious, or simply as a network of friends. This article arises from the context of an experience of more than 30 years of deep commitment to Higher Education (HE hereafter) of international academic communities (first at European and then at global level) engaged in student mobility, credit development, building international curricula as well as responding to the specific needs of projects in Thematic Networks. These were real Communities of Learning amongst whom ideas about HE developed and flourished. The article owes a lot to the questions shared with hundreds of academics who have been searching and exploring new ways of carrying

1 John N. Crossley and Constant J. Mews, eds., Communities of Learning: Networks and the shaping of intellectual identity in Europe, 1100-1500 (Turnhout: Brepols Publishers, 2011). 
out the unending task of opening the minds of younger generations not only to know and understand reality but also to imagine it differently, to judge the level of accuracy and the implications of their innovative perspectives and to search for ways of realizing them. This paper is heavily in debt to the international groups of colleagues who have shared the work of trying to design and deliver many international joint degrees, research and educational projects, and above all to the group of people who contributed to the systematization of processes and the development of concepts in the Tuning Project which seem to serve and be able to bridge continents achieving the acceptance of the international academic community. The Tuning Project, a Network of Communities of Learning, has been shaping the intellectual identity of HE for over ten years now, not only in Europe but in Latin America, USA, Russia, Africa... and other regions of the world. ${ }^{2}$

\section{Degrees in the age of convergence and diversity}

The speed at which changes in HE have occurred in the last two decades should not blur for us the time span that it has taken to arrive at the contemporary multi-task university with high levels of sophistication in degree design and delivery. ${ }^{3}$ The process has been very long, starting with a basic structure that remained the fundamental model. This evolved through time and become diversified in terms of subjects taught, the organisation of studies and the methods of teaching and examining, especially within national contexts. The structure of studies, however, remained quite fixed. Evolution in the last twenty years has been very rapid and was linked with international co-operation.

It was not until the Sorbonne and the Bologna Declarations ${ }^{4}$ that degrees would become the essential focal point of the European Higher Education

${ }^{2}$ More particularly, the authors would like to thank the leaders of Subject Area groups whose meta-profiles are cited as examples: Gustavo Pedrazo Aboytez, Irina Petrova, and Alex Rayón Jerez, Haddis Teklemariam and Karola Hahn for their meta-profiles; and Carlos Vargas Tamez for his contribution to the topic of relevance in Higher Education.

${ }^{3}$ Cf. Olaf Pedersen, The First Universities - Studium Generale and the Origins of University Education in Europe (Cambridge: Cambridge University Press, 1997) and Clara Tamayo Serrano, "El aporte cultural y educativo de la Baja Edad Media," Educación y Educadores 10, no. 2 (2007): 197-213.

${ }^{4}$ Sorbonne Joint Declaration: Joint declaration on harmonisation of the architecture of the European higher education system, (1998, May 25), http://www.bologna-berlin2003.de/pdf/ Sorbonne_declaration.pdf and The Bologna Declaration of 19 June 1999: Joint declaration of the European Ministers of Education (1999, June 19), http://www.bologna-berlin2003.de/pdf/ bologna_declaration.pdf 
Area and the need to reflect on the definition(s) and constitutive elements of the degrees was identified. It is at this time that an ever increasing number of countries have agreed to strive for a common definition of degrees, a common understanding of their constitutive elements and a common language to go beyond mere words and titles to the comprehension of the processes of learning that these are meant to provide. The centrality of degrees for the Bologna process is well recognised, however, the degree of success of the process is sometimes in question.

Studies on the level of achievement of the Bologna Reforms show the significance of the impact. ${ }^{5}$ However, as Barbara Kehm observes, while there is a considerable degree of convergence at the macro-level - in cases such as the system-wide introduction of a tripartite tiered structure of degrees or the use of the European credit - there is still considerable heterogeneity at the meso- (higher education institutions) and micro-levels (study programmes). ${ }^{6}$ She also considers that some elements of the Bologna reform agenda such as modularisation, learning outcomes and their assessment are not well understood in many systems and thus create a further element of divergence. This is in agreement with Veiga ${ }^{7}$ who observes that while at the macro level there is a clear element of increasing convergence, the main difficulty lies at the level of the individual countries. The latter argues that the change has taken place at the institutional and departmental level with curriculum reforms affecting professional roles and academic disciplines. The impact of the national factor is also recognized by $\mathrm{Sin}^{8}$ who, after the analysis of three countries through a qualitative approach using cultural interpretation theory points out that the prevalent perceptions of the Bologna reforms are decoded differently by academics in these three countries; showing that National cultural factors continue to play an important role in the context of decisions

${ }^{5}$ CHEPS, INCHER \& ECOTEC, The Bologna Process independent assessment: The first decade of working on the European Higher Education Area, Vol. 1 (2010), http://ec.europa.eu/ education/higher-education/doc/bologna_process/independent_assessment_1_detailed_rept. pdf and CHEPS, INCHER \& ECOTEC, The Bologna Process independent assessment: The first decade of working on the European Higher Education Area, Vol. 2 (2010), http://ec. europa.eu/education/higher-education/doc/bologna_process/independent_assessment_2_ cases_appendices.pdf

${ }^{6}$ Barbara M. Kehm, "Editorial," European Journal of Education. Special Issue: The Bologna Process revisited 47, no. 3 (2012): 343-347, doi: 10.1111/j.1465-3435.2012.01529.x

7 Amélia Veiga, "Bologna 2010. The moment of truth?" European Journal of Education. Special Issue: The Bologna Process revisited 47, no. 3 (2012): 378-391, doi: 10.1111/ j.1465-3435.2012.01532.x

${ }^{8}$ Cristina Sin, "Academic understandings of and responses to Bologna: a three-country perspective," European Journal of Education. Special Issue: The Bologna Process revisited 47, no. 3 (2012): 392-404, doi: 10.1111/j.1465-3435.2012.01533.x 
taken at Joint Ministerial level. However, due to the fact that the process initiated by the Bologna Declaration was and is a joint, collaborative experience, the evaluation of the success becomes as tentative and undogmatic as processes can be. It also becomes attractive and appealing to other regions ${ }^{9}$ who want to join in the collective search and learning and perhaps this speaks for its success and impact. ${ }^{10}$

\section{Defining degrees and their components}

Given the paramount importance of degrees and as an introduction to their profiles, it is worthwhile to analyse: first the definition of degrees and second the elements which constitute them. Five bodies and associations have been engaged in the definition of degrees and in the consideration of their components:

1. The Ministerial groups in meetings and declarations in which degrees had a significant level of centrality;

2. The group related to the Joint Quality Initiative later becoming the European Qualifications Framework;

3. The European University Association;

4. The Council of Europe-Higher Education; and

5. The Tuning Project.

The definition of Degrees from the Ministerial Group, with possibly the highest impact, due to its level of decision and also concreteness, comes from the Berlin Communiqué: "Ministers encourage the member States to elaborate a framework of comparable and compatible qualifications for their higher education systems, which should seek to describe qualifications in terms of workload, level, learning outcomes, competences and profile". ${ }^{11}$

${ }^{9}$ It must be noted that the word "region" is used throughout the present article to refer to those areas of the world who, far from being homogeneous or constitute one inseparable whole, choose to join their efforts and work together on (re) designing HE programmes to enhance HE quality and, in this way, make a first or a next step towards creating a common area of HE.

${ }^{10}$ Clifford Adelman, The Bologna Process for U.S. eyes: re-learning higher education in the age of convergence (Washington, DC, 2009), http://www.ihep.org/assets/files/ EYESFINAL.pdf, and Jane Knight, "A conceptual framework for the regionalization of higher education in Asia: application to Asia," in Higher education regionalization in Asia Pacific: Implications for governance, citizenship and university transformation, ed. John N. Hawking, Ka Ho Mok, and Deane E. Neubauer (London/New York: Plagrave Macmillan, 2012), 17-36.

11 The Berlin Communiqué: Realising the European Higher Education Area (2003), http://www.ond.vlaanderen.be/hogeronderwijs/bologna/documents/MDC/Berlin_ 
A definition of degrees was produced by the collective effort of a group made up mainly of Quality Agencies and Ministerial experts, which brought about A Framework of Qualifications of the European Higher Education Area: "Any degree, diploma or other certificate issued by the competent authority attesting that particular learning outcomes have been achieved, normally following the successful completion of a recognized higher education programme of study". ${ }^{12}$ This group also developed the Dublin Descriptors and contributed significantly with the concept of degree level, concentrating on the primary importance of the learning outcomes as the dominant characteristic of new degrees.

The European University Association offers a unique quantitative perspective through its Trends Studies, in which it considers that a large majority of institutions have implemented the new Bologna degree structure: from $53 \%$ of institutions in 2003 to $95 \%$ in $2010 .{ }^{13}$ However, in terms of degrees analysis, EUA mainly concentrates on the study of Master and Doctoral Degrees, particularly joint degrees as can be seen by analysing the publications of the European University Association in their web.

In relation to the Council of Europe, the contribution of Sjur Bergan ${ }^{14}$ needs to be highlighted. He comments on the existing state of affairs in Qualifications - Introduction to a concept and arrives at the synthesis of the elements which constitute a degree. These main elements he identifies as: Level, workload, quality, profile, and learning outcomes and competences, both generic and subject-specific competences. He also considers that degrees are a key element of higher education policies in general and of the Bologna Process in particular with the consequence that a proper understanding of qualifications is essential to making the European Higher Education Area a reality.

Given that the fifth body - the Tuning community is the focus of the present paper, this is discussed in a separate section although in terms of time, the systematic works of the academics starts early in 2001.

Communique1.pdf

12 Bologna Working Group on Qualifications Frameworks, A Framework for Qualifications of the European Higher Education Area, Copenhagen: Ministry of Science, Technology and Innovation, 2005, http://www .bologna-bergen2005.no/Docs/00-Main doc/050218_QF_EHEA.pdf

13 Andrée Sursock, and Hanne Smidt, Trends 2010: A decade of change in European Higher Education (European University Association: Brussels, 2010), http://www.eua.be/ publications/eua-reports-and-studies.aspx

${ }^{14}$ Sjur Bergan, Qualifications - Introduction to a concept (Strasbourg: Council of Europe Publishing, 2007). 


\section{Tuning definition and analysis of the degree components in a context of diversity}

In order to be consistent with the Tuning philosophy, diversity should be dealt with from the start. It was a clear concern in the Declarations of Sorbonne and Bologna and in the follow up Communiqués and it is absolutely vital to Tuning. The whole setting of the Tuning exercise is in an intercultural, international, inter-traditional-cultures context and the dialogue is an intercultural dialogue from beginning to end. The reaffirmation of diversity is an intrinsic motor in the development of the project and a constant concern in all its processes. The tension between the identification of the common and the richness of the diverse runs in each of the documents of the Tuning Project which now come from different parts of the world. In the first report in 2003, it is explained that: "The protection of the rich diversity of European education has been paramount in the Tuning Project from the very start". ${ }^{15}$ This reaffirmation will be found again and realized in thirty one new documents, some recently published, others due to be published in 2013 related to the new studies in Latin America, Russia and Africa.

The very first definition of the Bologna Degrees as such came from the Tuning Project. From the year 2001, the members of the Tuning Project worked on a definition that was laid out in the Glossary in 2003: "Qualification awarded by a higher education institution after successful completion of a prescribed programme of study. In a credit accumulation system, the programme is completed through the accumulation of a specified number of credits awarded for the achievement of a specific set of learning outcomes". ${ }^{16}$ In this Formative Phase of Tuning (2001-2005) the analysis of degrees took place under five different lines of investigation: (1) Generic competences; (2) Subject specific competences; (3) European credits; (4) Approaches to Teaching, Learning and Assessment; and (5) Programme quality. These lines gave birth to the first definition of Tuning degree ${ }^{17}$ components as: profile; learning outcomes and competences (generic and subject specific); level; workload; approaches to teaching/ learning and assessment; and programme quality.

15 Julia González, and Robert Wagenaar, eds., Tuning educational structures in Europe: Final Report. Phase One (Bilbao: University of Deusto and University of Groningen, 2003), 22.

${ }^{16}$ González and Wagenaar, Tuning educational structures in Europe: Final Report. Phase One, 257.

${ }_{17} \mathrm{Be}$ it a newly-created degree or a long-existing degree revised and re-structured in order to better match the current needs. 
Relating to the work of Tuning during this first stage, the identification of the components and the structuring of degrees constituted the main collective finding and set the scene for later developments. The articulation of the whole system slowly became a reality as the profile was expressed at a particular degree level in terms of learning outcomes and competences. These competences were then jointly defined and discussed in consultation with social partners, both in terms of importance and in terms of university performance. This empirical exercise provided a concrete setting, in which to reflect, discuss and welcome the diversity. The articulation of degrees in terms of credits (present in the definition of the glossary) revealed that the dimension of the time required to achieve the learning outcomes is an integral part of the whole concept of the degree. In addition, it was very important to consider the relevance and appropriateness of different methodologies of teaching, of learning and of assessing the desired learning outcomes. The final element: programme quality was the last element to be identified as of critical importance for ensuring the consistency of the whole system and the accountability required.

The image of the jigsaw puzzle where the different pieces fitted together (Figure 1 below) accompanied the second phase of Tuning (2006-2009), the phase of consolidation and expansion.

1. Define competences

2. Select and agree

3. Consult groups

4. Analyse results

5. Design profiles

6. Reflect workload

7. Formulate learning strategy

8. Indicate assessment

9. Check quality

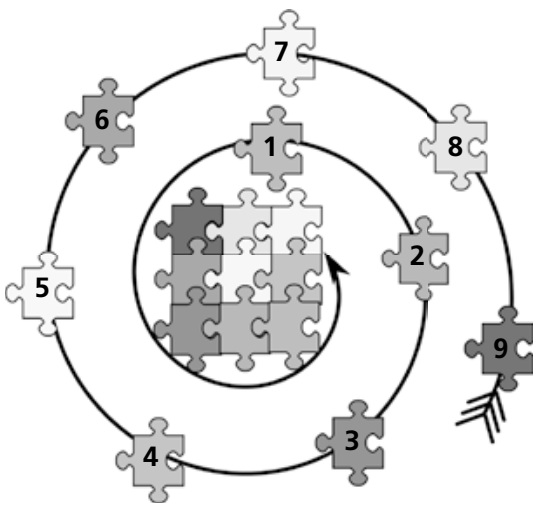

Figure 1

Bringing degree development elements together.

A further essential identity mark inherited during this period related to the Reference Points. The Reference points, or the set of competences and learning outcomes which the Tuning Communities of Learning considered as 
essential for the identification of degrees in different fields of study gained popularity, validity, depth and recognition by academic communities all over the world. The development of further reference points both at the level of new disciplines as well as in relation to new areas brought further elements for reflection.

The Latin American experience revealed the importance of academic credits for a quality development of degree profiles. ${ }^{18}$ While in Europe, credits were introduced primarily as a tool for promoting mobility, in Latin America the experience proved that a quality degree could not be designed without an internal understanding of the units of learning and their temporal demands. ${ }^{19}$ At the same time the three forces which had been at the root of the Tuning concept of degrees from the beginning, became stronger. Tuning Degrees could be identified with the search for relevance, recognition and quality. This awareness of the fundamental forces driving the process brought further insights and direction.

These experiences, debates and further analysis brought the Tuning Project to the third period (2010-2013) which could be referred to as the specialization phase. In fact, the different components of the Tuning analysis of degrees can be understood from a more wholesale approach. There are three specific clusters of processes in relation to the development of degrees. The first cluster relates to the development of degree profiles, the second relates to academic programmes and the third deals with the personalised path for each of the learners. Each of these processes has two components: one of design and the other of implementation.

While the rest of this article will concentrate on the set of processes relating to the designing of degree profiles, it is important to emphasize that the other two clusters of processes are of great significance. Updated, socially and professionally required profiles could be built satisfactorily but these would be misleading if they were unsuccessfully transformed into programmes to guarantee their implementation or if they were inadequate for the real-life students who, in practice, tried to follow them.

An educational programme transfers the profile into the curriculum. The programme needs to be designed to assure consistency between the profile promised and the learning processes at work, between the set of competences and the ways to develop and acquire them. To design an academic programme is an exercise in consistency. This consistency needs to touch every element:

${ }_{18}$ See CLAR: Latin American reference credit (Bilbao: University of Deusto, 2013).

19 This article, however, is not going to discuss this crucial element in any more detail. Other sections deal at length with this issue, particularly on the section on credits in reference with the developments in Latin America. 
the learning strategies involving the specific elements of theoretical and practical learning, the international paths involved, the planned experiences and the levels at which the competences need to be developed as well as the number of academic credits devoted to each educational component of the programme.

The last cluster relates to the path of the individual learner. In a studentcentred learning system, each learner needs to follow a personal road that takes him/her through a particular programme. Relevant to this context is the evaluation of how the student initiates the process, his/her starting point, the recognition of prior learning achieved, as these elements are important to the understanding of individual strengths and weaknesses and very specially the personal motivations and aims which can be the engines bringing the process to a successful completion. A further crucial consideration is the awareness of specific styles of learning. This is particularly important in an age where ICT and images invade the mind and may give special importance and necessity to capacities such as abstract thinking.

During recent years in the Tuning process, the tasks of developing degrees have become quite diverse and demanding. Looking at the division of labour in universities, it may be considered as a specialisation issue. Since, there are some who prepare the profiles (profile designers) ${ }^{20}$ others who specialise in the articulation of the different elements of the programme to implement the profiles (programme developers). Still others are in charge of accompanying and stimulating the learning process (the teachers) or of following the personal road of each of the people's learning paths (the tutors).

The rest of this article will concentrate on the development of the first cluster - degree profiles - and the work of those who are responsible for developing them.

\section{Building degree profiles}

The definition of degree profiles has advanced significantly through reflection during the latest period of the Tuning project. It appeared first as a rather tentative definition in A framework for Qualifications of the European Higher Education Area: "either the specific (subject) field(s) of learning of a qualification or to the broader aggregation of clusters of qualifications or programmes from different fields that share a common emphasis or purpose

${ }^{20}$ The importance of training needs to be emphasised at this point and for every one of the tasks related to profile and programme design and delivery. Training or lack of it may make the entire curriculum reform miss the target or turn it into a success. 
(e.g. an applied vocational as opposed to more theoretical academic studies". ${ }^{21}$ The text points out, then, to the work of the Tuning Project as a reference for profile building. In fact, reshaping slightly the definition given in A Guide to Formulating Degree Programme Profiles ${ }^{22}$ it may be concluded that a Degree profile describes the specific characteristics of a qualification in terms of learning outcomes and competences.

Another definition is offered by the Degree Qualifications Profile. This interesting combination for the American context supported by the Lumina Foundation and where Degree profiles encompass the qualifications framework, which are two different concepts in the European setting, defines it as "A Degree Profile - or qualifications framework - illustrates clearly what students should be expected to know and be able to do once they earn their degrees - at any level. This Degree Profile thus proposes specific learning outcomes that benchmark the associate bachelor's and master's degrees. ${ }^{23}$

However, the latest definition of a degree profile for Tuning was given on the $21^{\text {st }}$ of November 2012, after a long process of reflection and debate within the standing projects of Tuning in Latin America, Russia and Africa, and describes the degree profile as a combination of forces around four poles:

1. The needs of the subject area (from the local to the more international context)

2. The meta-profile ${ }^{24}$ of a specific field, the structured points of reference

3 . The consideration of future trends in the profession and society

4. The specific mission of the institution.

Next, reference will be made of each of the elements and their impact in Degree Profiling.

\section{Analysis of social needs and professional demands}

The issue of relevance is paramount for the design of degree profiles. Without a doubt, the analysis of the relationship between university and

${ }^{21}$ Bologna Working Group on Qualifications Frameworks, A Framework for Qualifications of the European Higher Education Area, 30.

${ }^{22}$ Jenneke Lokhoff et al., A Tuning guide to formulating degree programme profiles (Bilbao, Groningen, The Hague: University of Deusto, 2010).

${ }^{23}$ Lumina Foundation, The degree qualification profile. (2011), 1, http://www. luminafoundation.org/publications/The_Degree_Qualifications_Profile.pdf

${ }^{24}$ A meta-profile is a representation of the structure and combination of competences which gives identity to a subject area, the whole concept will be later developed. 
society is at the core of the theme of relevance in higher education. Nevertheless, examining these relations should be conducted carefully. Tünnermann and de Souza warn that when the relevance of higher education is addressed, there is a tendency to reduce the concept to that of the appropriate response to the demands of the economy or the business sector. They assert that higher education should indeed meet these demands, but that relevance transcends economic and labour concerns. They argue that the societyuniversity tandem should be examined in a broader perspective taking account of the challenges and demands presented to it by society as a whole. What is involved is translating the overall aims and purposes of society in terms of the tasks incumbent upon higher education, in both its quantitative and its qualitative aspects. ${ }^{25}$

Given the multiplicity of stakeholders and the differentiated expectations that they place on higher education, striking a balance between employability, citizenship, and personal growth, becomes a challenge. In an attempt to address such a challenge, Tuning has developed, from the start, a particular methodology to build and re-develop degree programmes that respond to these multiple aspirations. This exercise requires a better articulation between universities, and the problems as well as society and the world of work, basing long-term orientations on societal aims and needs, including respect for cultures and environmental protection. One more concern is the identification of the right mix of skills and their translation to curricula so that higher education graduates may be able to face current - and prospective - needs, to satisfy employment and social demands, and to contribute to the betterment of their societies and closer environments.

In addition to these broad social aspirations, there are other academic and labour imperatives that need to be met, namely the needs of the knowledge society. The OECD, for example, stresses the role of tertiary education in fostering research, innovation and development, and suggests the development of educational policies articulating clearly the nation's expectations of the tertiary education system and aligning priorities of individual institutions with the nation's economic and social goals. ${ }^{26}$

Tuning aims at identifying and addressing the needs of the productive sector, of the economy, of society as a whole, and the needs of individual learners within a particular area of study and mediated by their specific social

${ }^{25}$ Carlos Tünnermann Bernheim, and Marilena de Souza Chaui, Challenges of the university in the knowledge society, five years after the World Conference on Higher Education, UNESCO Forum Occasional Papers Series, Paris: UNESCO, 2003, 11.

${ }^{26}$ OECD, Tertiary Education for the Knowledge Society (Paris: OECD Publishing, 2008). 
and cultural contexts. In order to strike a balance between these varied needs, goals and aspirations, Tuning has undertaken consultations with leading persons, key local thinkers and experts from industry, academia, and civil society, and working groups that include all stakeholders. These practices are explained below.

The search for relevance is one of the driving forces behind Tuning exercises destined to:

1. Understand, discuss and enrich the definition of generic and subject specific competences;

2. Reflect critically on the needs and the strengths of their own region and the thematic and professional fields related to their own field;

3. Know how other regions of the world position themselves in this respect;

4. Provide for a frame of reference for later individual Degree profiling;

5. Be aware of shortages and gaps present in the area;

6. Reflect on the characteristics of the citizens who can best contribute to a culture of the region and world culture of democracy, sustainability and human rights; and

7. Consult with other discussion groups selected in each of the academic communities.

In order to accomplish this first collective task of defining generic competences for the specific region, each Subject Area Group is asked to prepare a list of the generic/ transversal competences considered to be relevant to their perspective region. They reflect and discuss first their own understanding of the socio-economic needs of the area. They, then, analyse lists found in the current literature and those selected by previous Tuning groups such as the 31 generic competences identified in Europe, ${ }^{27} 27$ identified in Latin America, ${ }^{28} 30$ in Russia ${ }^{29}$ and 18 for Africa amongst others. In addition, there are the contributions from different participants in the project. This task is finalised when the group has understood, broadly discussed and reached consensus on a selection of competences thought to be the most appropriate for the region. This is done from a rich intercultural perspective since the participants come from different countries and cultural

${ }^{27}$ See the list of generic competences agreed by Europe on the website of the Tuning Europe project: http://tuning.unideusto.org/tuningeu/

${ }^{28}$ See the list of generic competences agreed by Latin America on the website of the Tuning Latin America project: http://www.tuningal.org

${ }^{29}$ See the list of generic competences agreed by Russia on the website of the Tuning Russia project: http://www.tuningrussia.org 
backgrounds. The final stage takes place at the general group level where understanding, debate and agreement has to be reached for all of all the Subject Area Groups involved. It is a process of enrichment and responsibility raising awareness, where relevance takes shape and becomes the common language at group level.

The second task is similar to the first and relates to defining specific competences for a particular Subject Area. The questions reach another level of specificity. From their particular background, how would each group of academics define their specific area? Which competences are the core contributions of each of the areas to the development and advancement of society? Which are the core elements in a particular subject area, field of knowledge or area of interest and how could they be determined? Which competences can be considered core for those attaining a qualification in this particular field and at each of the levels? Which, while not being core, are most needed in the region? The intercultural debates end with the final choice of competences that can define the specific cohorts of learners who reach a degree.

A major check on relevance needs to be undertaken against the entire list which has been agreed. The analysis seeks to measure the degree to which the competences selected by academics are seen by a broader society as leading to basic required levels of employability and active citizenship. This search for relevance has recently been redefined as: "preparing for sustainable employment; preparation for life as active citizens in democratic societies; personal development; [and] development and maintenance, through research, teaching, and learning, of a broad, advanced knowledge base" ${ }^{30}$ It is the personal, professional, institutional and social responsibility, which could be referred to in different ways, which responds to the necessity of placing knowledge and capacity at the service of social development and innovation.

The next task relates to the process of consultation. This requires (1) understanding of the reasons behind the consultation as well as the value attached to this practice; (2) selecting the mode of consultation which is considered most appropriate; (3) understanding the technical requirements; (4) acknowledging the existing traditions and literature; and (5) identifying, discussing and agreeing on the most relevant groups to be consulted (other

${ }^{30}$ Recommendation $\operatorname{Rec}(2007) 6$ of the Committee of Ministers to member states on the public responsibility for higher education and research cited in Snežana Samardžić-Marković, "A word from the Council of Europe's Director General for Democracy," in Reimagining democratic societies: A new era of personal and social responsibility, eds. Sjur Bergan, Ira Harkavy, and Hilligje van't Land (Strasbourg: Council of Europe Publishing, 2013), 7. 
academics, employers, students, graduates, professional bodies, government bodies, associations of citizens, platforms, think-tanks...).

Once the mode of consultation has been agreed and the process of that consultation has been completed, the final stage in this practical process of searching for social relevance refers to the analysis of the findings. This is carried out jointly by the group and special care is taken not to lose any of the contributions coming from the different cultural perceptions which can enlighten the understanding of the concrete reality, the most urgent needs, the recognised strengths, weaknesses, opportunities and threats and of how they should be planned for in terms of educational measures, taking into account the characteristics of the specialists and the citizens, the people who could offer an answer.

\section{The development of meta-profiles}

In the first definition of profiles given above, there was a reference to "the specific (subject) field(s) of learning of a qualification". It is in the tradition of Tuning to build reference points for each of the fields and to offer an understanding of the specific academic area. Communities of Learning from different parts of the world have identified the core elements in terms of competences which would make a degree identifiable and hence recognisable. The analysis of the subject area is an integral part in the Tuning Project. One of the first steps is the debate on what each discipline is about, what the graduates normally do after completing the degree, how the field is structured and linked to other fields. The joint reflection on the specific subject area, the understanding of its identity as an academic field, the essence of its contribution to society and the mapping not only of the field but also of the possible branches and jobs required are a necessary building block in the development of the Tuning process and the essence of future developments. This is a pre-condition, a step and a starting point towards any degree profilebuilding endeavour.

The need to build degrees capable of gaining recognition across the European Higher Education Area was one of the earliest aspirations of the Tuning experience, as well as a driving force. Debates on the core elements of every area constitute one of the essential processes in Tuning. This seeks the collective understanding of a particular field as well as the agreement on what constitutes core as opposed to diverse or specialized competences. It is critical to differentiate between the core elements and the specialized aspects introduced for different reasons into the different subject areas. As a result of this work, lists of specific competences are built and discussed in the different 
regions giving those participating ownership over the comprehension of each of the fields as well as ownership over the results.

During the last two years a new step has been developed: Beyond providing the specific competences and carrying the consultation and the definition of the reference points, the Tuning participants undertook a further exercise, that of analysing these reference points, discussing their classification, structure and desired weight. Such questions as how they could be grouped, and as what are the linkages and the differences in importance, have led to the creation of meta-profiles. Tuning Subject Area Groups are real communities of practice following Eckert's definition ${ }^{31}$ perfectly ready to carry out this task at regional level since they are formed by highly experienced academics in their respective areas. Besides, the Tuning Communities are continually open to parallel groups from other regions and other academic fields/areas of practice and can be, therefore, truly considered Communities or Networks of Learning as explained above. Subject Area Groups do not only agree on the lists of components that identified the core and the level of diversification but go further to classify the findings and create a structure, portraying how they understand the ways in which the components relate to each other. These are called meta-profiles.

Thus, a meta-profile is a representation of the structure and combination of competences which gives identity to a subject area. A meta-profile is a mental construct that categorizes competences into major recognized components and illustrates their interrelationship. The meta-profiles have become fruitful tools for reaching an understanding of a field of study at the level of the individual region. This brings a number of advantages. The first is the capacity to create collective understanding and to raise the level of the debate about essential elements and secondary additions in the field of medicine, history, agriculture or architecture, for example. Besides, this collective understanding is important for reaching common comprehension of degrees since it focuses on the centrality of the reference points and its weight in an educational programme. This representation also offers the possibility to reflect and discuss further on the combination of elements. This reflection and debate should normally lead to greater depth in the understanding and quality.

The second contribution relates to recognition. Recognition, very generally speaking, means validating a learning experience. Kohler considers that at a "macro-level", which is probably the more common interpretation of

${ }^{31}$ Penelope Eckert, "Communities of Practice," in Encyclopedia of language and linguistics, ed. Keith Brown (Amsterdam: Elsevier Ltd., 2006), 638-685, http://www. sciencedirect.com/science/article/pii/B0080448542012761 
the word recognition is the question of whether or not an academic qualification acquired in one country is valid as a starting point for entering into the labour market - in as much as it is academically based - or for enrolling in a postgraduate programme in another country. In this respect, the focus is on the problem of whether or not an academic qualification acquired in one country is approximately equal to a learning experience, namely a qualification, acquired in another country. "In the case of Europe, this relates to the common European labour market, an essential part of which is the mobility of people within Europe aided by the recognition of qualifications across borders". ${ }^{32}$

Tuning maintains that what is relevant for recognition is to have a proof of having achieved the desired set of outcomes. This approach allows for a broad variety of routes, approaches and processes to achieve the goals. Historians, for example, can study past developments in different geographical settings. They can do so by reference to a very wide range of methodologies. They can also explain contexts citing different traditions, variations of cultural institutions and events which belong to different contexts. However, the outcomes should be comparable in terms of the graduates' capacity to analyse societies in their evolution across time and transparent in the methodologies and rigour used in their research or in the language in which their findings are presented while allowing for academic debate to continue and deepen.

The conscious decision to focus on outcomes leads directly to the relevance of meta-profiles for recognition. The meta-profile presents an understanding not only of the core elements and their description but also of their identification and explanation in a language which is understood and readable. They offer the location, importance and weight of the different factors which make up the whole image. The meta-profiles give the contours within which degrees can be identified and recognised because the key elements are well portrayed.

The third advantage of developing meta-profiles is constituted by the possibilities they offer in terms of the development of joint degrees. Through the consideration of the meta-profile, the main elements of a degree profile may be identified and responsibilities for its construction be shared, based on a common understanding of the whole area. In this age of transnational degrees, tools which favour common understanding are particularly helpful.

Finally, meta-profiles provide a new and different path to regionalisation ${ }^{33}$ and ultimately to globalisation. In Tuning, meta-profiles are built at the level of the region: Europe, Latin America, Africa.... jointly built, owned and later

32 Jürgen Kohler, "Quality assurance, accreditation, and recognition of qualifications as regulatory mechanisms in the European HEA," Higher Education in Europe 28, no 3 (2003): 327.

${ }^{33}$ Cf. Knight, "A conceptual framework". 
validated at regional level. There is normally a further level of comparison with other world regions and eventually at global level. However, this way of reaching the global level implies that it is again (as everything in Tuning) a bottom up approach, that is to say from the regions upwards, but in this case, each region owns its own processes and may agree to compare or share with another only if and when and to the extent they choose to do so. This way, the Tuning methodology respects the genuine elements of the local which are at the heart of the process. This makes a significant difference in terms of developing global indicators - bottom up rather than top-down - and creates a new and improved path to reach global indicators.

In order to clarify the concept of the meta-profile some examples are provided below. The case of the meta-profile for Chemistry developed by Tuning Latin America is used as the primary example. It will be compared briefly with two others, the one from a Tuning group in Russia and the other from Africa.

The Chemistry Subject Group from Latin America ${ }^{34}$ had taken the following path. The first stage was the very thorough analysis of the competences both generic and subject specific, redefining and reducing them to 17 which were, after a debate, grouped into four major categories called Factors:

- Factor 1 relating to the Learning Process and defined in terms of knowledge, the generic and specific competences related to it (see below).

- Factor 2 was identified as related to Social Values, marking their achievement in terms of the capacity to develop an autonomous and effective ability to develop all the different social, cultural and managerial aspects, ethical practice and knowledge to contribute to the best use of natural renewal and non-renewable resources to the benefit of humankind.

- Factor 3 was identified as the Technological and International Context, including the capacity to communicate in other languages, using diverse and most modern technological and computing resources to develop in the international arena.

- Factor 4 relates to interpersonal competences, focusing on the capacity to take decisions, develop autonomy in professional life, capacity to work in interdisciplinary and trans-disciplinary context related to Chemistry. Also included here is the capacity to organise, plan both individual and team work and solve new situations.

${ }^{34}$ Gustavo Pedraza Aboytes, ed., Higher Education in Latin America. Reflections and Perspectives in Chemistry (Bilbao: University of Deusto, in press). 


\section{So the Chemistry competences were grouped as follows:}

Table 1

Chemistry subject area Generic (G) and Subject-Specific (S) competences organised in factors. Latin America (Adapted from Pedraza Aboytes, "Higher Education")

\begin{tabular}{|c|c|c|}
\hline Knowledge & Generic competences & Subject-Specific Competences \\
\hline \multicolumn{3}{|c|}{ Factor 1: Learning process } \\
\hline $\begin{array}{l}\text { Understands the } \\
\text { nature and properties } \\
\text { of atoms and } \\
\text { molecules, the laws } \\
\text { and principles that } \\
\text { determine their } \\
\text { interaction and cause } \\
\text { chemical reactions } \\
\text { and other relevant } \\
\text { phenomena. } \\
\text { Understands and } \\
\text { applies knowledge of } \\
\text { chemistry critically in } \\
\text { order to analyse, } \\
\text { elaborate, synthesise, } \\
\text { describe and obtain } \\
\text { chemical compounds } \\
\text { that have scientific or } \\
\text { industrial use. }\end{array}$ & $\begin{array}{l}\text { 1G. Capacity for } \\
\text { abstract thinking, } \\
\text { analysis and synthesis. } \\
\text { 2G. Capacity to learn } \\
\text { and keep up to date. } \\
\text { 3G. Critical and self- } \\
\text { critical abilities. } \\
\text { 4G. Ability to find } \\
\text { and analyse } \\
\text { information. } \\
\text { 5G. Oral and written } \\
\text { communication. }\end{array}$ & $\begin{array}{l}\text { 1S. Capacity to apply knowledge and } \\
\text { understanding of chemistry to solving } \\
\text { qualitative and quantitative problems. } \\
2 \mathrm{~S} \text {. Understand concepts, principles and } \\
\text { basic theories of Chemistry. } \\
3 \mathrm{~S} \text {. Interpret and evaluate data obtained } \\
\text { through observing and measuring, relating } \\
\text { these to the theoretical knowledge. } \\
4 \mathrm{~S} \text {. Capacity to recognise and analyse } \\
\text { problems and develop strategies to solve } \\
\text { these problems. } \\
5 \mathrm{~S} \text {. Ability to develop and apply analytical } \\
\text { techniques. } \\
6 \mathrm{~S} \text {. Capacity to stay up to date with } \\
\text { developments in Chemistry. } \\
7 \mathrm{~S} \text {. Capacity to plan, design and implement } \\
\text { research projects. } \\
8 \mathrm{~S} \text {. Mastery of chemical terminology, } \\
\text { nomenclature, conventions and units. } \\
9 \mathrm{~S} \text {. Knowledge of the major synthetic routes } \\
\text { of Chemistry. } \\
10 \mathrm{~S} \text {. Knowledge of other scientific } \\
\text { disciplines that facilitate understanding of } \\
\text { Chemistry. } \\
11 \mathrm{~S} \text {. Ability to monitor chemical properties, } \\
\text { events or changes through observation and } \\
\text { measure and to document these in a } \\
\text { systematic and reliable form. } \\
12 \mathrm{~S} \text {. Familiarity with the Laboratory Good } \\
\text { Practices. } \\
13 \mathrm{~S} \text {. Capacity to act with curiosity, initiative } \\
\text { and entrepreneurial spirit. } \\
16 \mathrm{~S} \text {. Understanding of scientific } \\
\text { epistemology. }\end{array}$ \\
\hline \multicolumn{3}{|l|}{ Factor 2: Social Values } \\
\hline & $\cdots$ & $\ldots$ \\
\hline \multicolumn{3}{|c|}{ Factor 3: Technological and international context } \\
\hline$\cdots$ & $\ldots$ & $\ldots$ \\
\hline \multicolumn{3}{|c|}{ Factor 4: Interpersonal Abilities } \\
\hline$\cdots$ & $\cdots$ & $\ldots$ \\
\hline
\end{tabular}


The first factor related to knowing, the second to knowing how to be, the third to knowing how to do and finally the fourth looked at to knowing how to be and do.

With this classification a matrix of generic and specific competences for the field of Chemistry was developed (Table 2 below). As a product of the group's reflection and debate, the corresponding relationship between generic and specific competences was found, the relationships between then portrayed according to the classification factors.

Table 2

Chemistry subject area competences: Matrix

Generic Competences (GC) and Subject-Specific Competences (SC) most relevant for the subject area are grouped into factors. (Adapted from Pedraza Aboytes, "Higher Education")

\begin{tabular}{|c|c|c|c|c|c|c|c|c|c|c|c|c|c|c|c|c|c|}
\hline Factor & $\mathrm{GC} / \mathrm{SC}$ & 1 & 2 & 3 & 4 & 5 & 6 & 7 & 8 & 9 & 10 & 11 & 12 & 13 & 14 & 15 & 16 \\
\hline \multirow{5}{*}{1} & 1 & $\mathrm{x}$ & $\mathrm{x}$ & $\mathrm{x}$ & $\mathrm{x}$ & X & & $\mathrm{x}$ & & $\mathrm{x}$ & $\mathrm{x}$ & X & & & & & $\mathrm{x}$ \\
\hline & 2 & & & & $\mathrm{x}$ & X & $\mathrm{x}$ & $\mathrm{x}$ & $\mathrm{x}$ & $\mathrm{x}$ & $\mathrm{x}$ & $X$ & $X$ & $\mathrm{x}$ & & & \\
\hline & 3 & & & $\mathrm{x}$ & $\mathrm{x}$ & & & $\mathrm{x}$ & & & $\mathrm{x}$ & $X$ & $X$ & $\mathrm{x}$ & & & \\
\hline & 4 & $\mathrm{x}$ & $X$ & $\mathrm{x}$ & $\mathrm{x}$ & $X$ & $\mathrm{x}$ & $\mathrm{x}$ & $\mathrm{x}$ & $\mathrm{x}$ & $\mathrm{x}$ & $\mathrm{X}$ & $X$ & $\mathrm{x}$ & & & $\mathrm{x}$ \\
\hline & 5 & & & & $\mathrm{x}$ & & & $\mathrm{x}$ & & & $\mathrm{x}$ & X & & $\mathrm{x}$ & & & \\
\hline \multirow{5}{*}{2} & 6 & & & & & & & & & & & & & $\mathrm{x}$ & & $\mathrm{x}$ & \\
\hline & 7 & & & & & & & & & & & & & $\mathrm{x}$ & & & \\
\hline & 8 & & & & & & & & & & & & & $\mathrm{x}$ & X & $\mathrm{x}$ & \\
\hline & 9 & & & & & & & & & & & & & $\mathrm{x}$ & X & $\mathrm{x}$ & \\
\hline & 10 & & & & & & & & & & & & & $\mathrm{x}$ & $X$ & $\mathrm{x}$ & \\
\hline \multirow{3}{*}{3} & 11 & & & & & & & $\mathrm{x}$ & & & & & & & $X$ & & \\
\hline & 12 & & & & & & & $\mathrm{x}$ & & & & & & $\mathrm{x}$ & X & & \\
\hline & 13 & & & & & & & $\mathrm{x}$ & & & & & X & $\mathrm{x}$ & X & $\mathrm{x}$ & \\
\hline \multirow{6}{*}{4} & 14 & & & & $\mathrm{x}$ & & & $\mathrm{x}$ & & & & & X & $\mathrm{x}$ & & & \\
\hline & 15 & & & & & & & $\mathrm{x}$ & & & & & & $\mathrm{x}$ & & & \\
\hline & 16 & & & & $\mathrm{x}$ & & & $\mathrm{x}$ & & & & & & $\mathrm{x}$ & & & \\
\hline & 17 & & & & $\mathrm{x}$ & & & $\mathrm{x}$ & & & & & X & $\mathrm{x}$ & & & \\
\hline & 18 & & & & $\mathrm{x}$ & & & $\mathrm{x}$ & & & & & X & $\mathrm{x}$ & & & \\
\hline & 19 & & & & $\mathrm{x}$ & & & $\mathrm{x}$ & & & & & X & $\mathrm{x}$ & & & \\
\hline
\end{tabular}


Based on the matrix obtained, they built two maps of competences: one with $100 \%$ correlation between the competences and the other with 50\% correlation as shown in Figure 2.

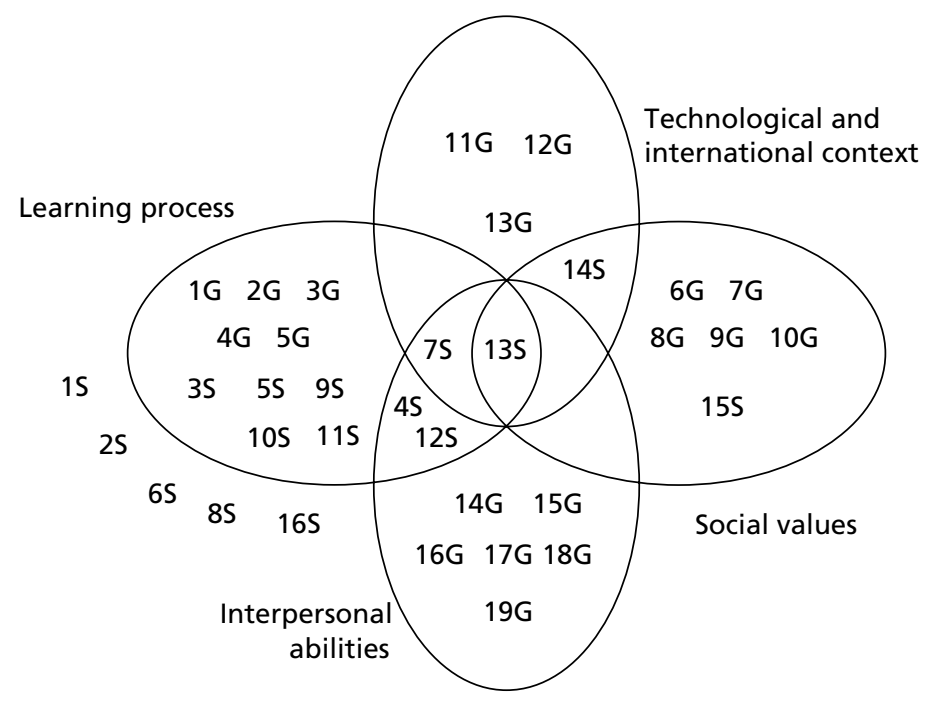

Figure 2

Chemistry subject area meta-profile

The Figure shows interrelation of the Four Factors distinguished

(with a coincidence greater than $50 \%$ ), with their respective Generic (GC) and

Subject-Specific (SC) Competences

(Adapted from Pedraza Aboytes, "Higher Education").

This presents an image of the position of each of the competences and the degree of centrality as they were considered for the Latin American Degree Profile in Chemistry. Five competences were shown as very central to the Chemistry degree: 13S (capacity to act with curiosity, initiative and entrepreneurial spirit; absolute centrality for all factors), 7S (capacity to plan, design and implement research projects), $4 \mathrm{~S}$ (capacity to recognize and analyse problems and develop strategies to solve these problems), 14S (knowledge, ability to apply it and understanding of legal contexts), $12 \mathrm{~S}$ (familiarity with laboratory good practices). Several conclusions can be drawn but it is clear that these five competences appeared at the heart of any Chemistry degree and they are critical for identity and recognition.

Different methodologies for developing meta-profiles are analysed and presented in the intellectually challenging and thought provoking book the 
Tuning Meta-profiles for Latin America (in press, in Spanish, Portuguese and English) where 15 different scientific areas explained the roads followed to reach their representations. Each field (agronomy, architecture, business, civil engineering, chemistry, education, geology, history, informatics, law, mathematics, medicine, nursing, psychology and physics) is consistent with its own approach and develops its own mental understanding after a period of research and joint debate. This book is supplemented with 15 publications where every subject area group not only presents the reference points and meta-profile for the area and the methodology used but also the analysis carried out about future trends for the area, and reflections on workload for the specific field in the different Latin American countries as well as the development of a number of competences important for the scientific field.

A similar series of publications has been prepared by the Tuning Russia project and has been published in June 2013 in Russian and in English. They relate to 11 scientific areas: ecology, economics, education, environmental engineering, foreign languages, ICT, interpreting and translation, law, management, social work and tourism. The ICT subject area group used the notion of meta-competences, and their approach and solution will be taken as an example here. Meta-competences are the main categories into which the learning outcomes of a certain higher-education professional area can be grouped. Introduction of the notion of meta-competences permits articulating major strands of competential development and makes clear the academic and professional contexts to which the degrees offered within this academic and professional area are related and to which, consequently, the degree profiles need to be linked.

The final version of the ICT subject area meta-profile is presented in Figure 3, with the different axes and relationships of competences.

The diagram of meta-profile for the ICT sub-area concerned is presented in the figure, with the different axes and relationships of competences. In order to get to this representation, the 20 key competences defined were analyzed one by one. Each competence was located into the cluster of competences with which it was the most closely connected, or, if there was not such cluster, a new cluster was created for this competence. By applying this procedure, the five groups of competences were formed and the metacompetences were identified to represent the core of degrees in the ICT subject area. The core element of the final set of meta-competences is the ability to join the professional community (MGC-3). This meta-competence is achieved by mastering both generic and subject-specific competences, considering ICT sub-disciplines (according to Computing Curricula) and Russian educational standards in this area. 


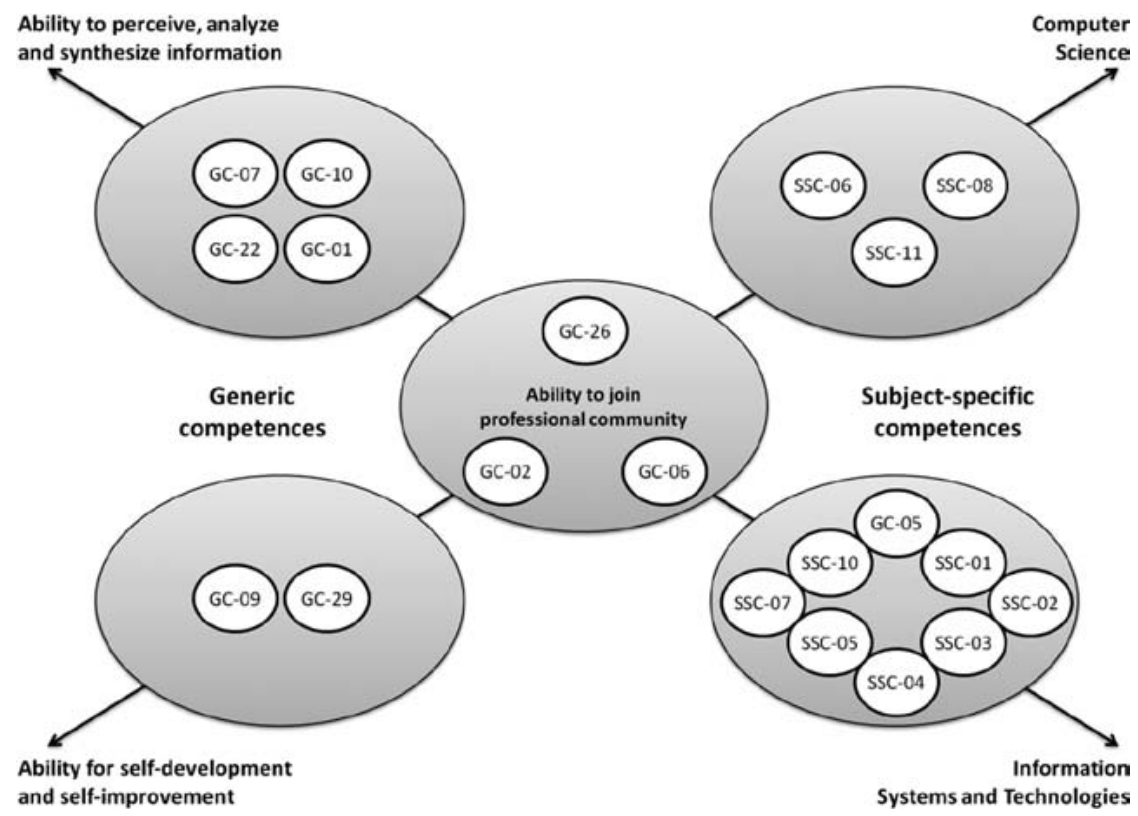

Figure 3

ICT subject area meta-profile. Russia ${ }^{35}$.

The generic meta-competences in question are the ability to perceive, analyze and synthesize information (MGC-1) and the ability for selfdevelopment and self-improvement (MGC-2). The subject-specific metacompetences are the ability to understand, apply and develop mathematical knowledge, basic laws of natural science and fundamentals of information technologies (MSSC-1), that is the "group of competences related to Computer Science sub-discipline of ICT" and the ability to design, develop, implement and manage life cycle processes of information systems and technologies (MSSC-2), that is the "group of competences related to Information Systems and Technologies sub-disciplines of ICT".

The last example considered here is the case of the Meta-profile for Civil Engineering in Africa (Figure 4 below). After following the processes of identification and consultation as in the previous cases, the experts worked

${ }^{35}$ Irina Petrova et al., Tuning Russia. Reference points for the design and delivery of degree programmes in Information and Communication Technologies (Bilbao: University of Deusto, 2013). 
on clustering the generic and subject specific competences which gave an understanding of their respective importance in the degree. ${ }^{36}$

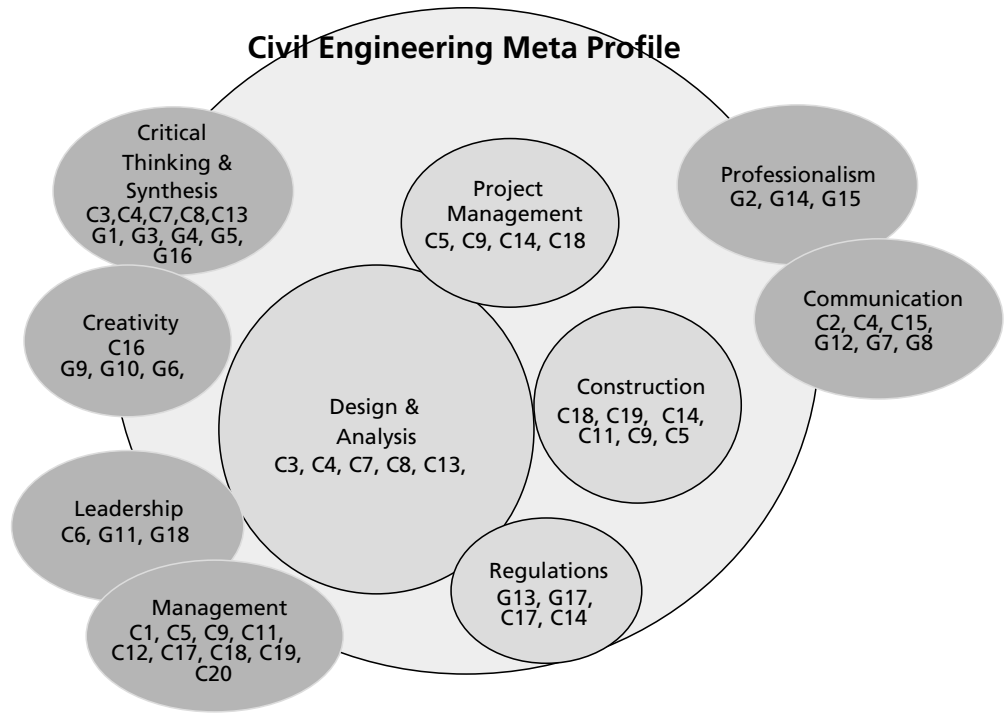

Figure 4

Civil engineering meta-profile (From Tuning Africa Civil Engineering Subject Area Group, "Final Report", 33).

The group of competences in the centre relates to the capacity to develop processes intrinsic to the field which are important to secure the identity of the area. In addition, it was critical, in the second stage, to make sure that these competences would have an appropriate place in the design of the programme. It was also of great relevance for delivery. These competences relate to the capacity to understand the characteristics of the field and be able to make them operational as a result of the understanding.

The group ${ }^{37}$ concurred that the three core clusters mentioned above were identified as central for Civil Engineering curricula. They were also in agreement about the weight of each of the components, with the capacity for Design and Analysis taking up a larger proportion of time. The group

${ }^{36}$ Tuning Africa Civil Engineering Subject Area Group, Final Report "Tuning and Harmonization of Higher Education in Africa" Pilot Project. Civil Engineering (Bilbao: University of Deusto, in press).

${ }^{37}$ Coordinated by Haddis Teklemariam and Karola Hahn. 
identified 18 generic competences that are crucial for a Civil Engineering Graduate. These 18 generic competences were then clustered at one level below that of the core clusters. The clusters were for the following areas: Critical Thinking, Professionalism, Creativity, Communication, Leadership and the ability to apply Regulations. After following a lengthy process of condensing the 54 subject specific competences as well as looking at the generic competences, the group identified the critical competences and systematized them into mega clusters.

The six clusters, that are those at one level below the core clusters, were further grouped together into Critical Thinking \& Synthesis and Creativity. The second grouping is Leadership and Management and the third is Professionalism and Communication. These groupings were done to show that in an African Civil Engineering context, a graduate would need to acquire the same level of skill in all these clusters. The final step of setting up the Civil Engineering Meta Profile was to combine the core clusters with the clusters as shown in the graph. The core clusters are grouped together in a knowledge sphere and this sphere symbolises the capacity to handle in its different dimensions the knowledge that a student should gain in her/his undergraduate course. This includes learning all the different ways and methods of designing in the four different fields of Civil Engineering. The final step was to link optically the generic and subject specific competences to the Meta Profile that was identified. It can also be seen that certain competences appear more than once in the different clusters, as it is believed that the information can be transferred to the student in more than one field and/or in more than one way.

This development of Meta-Profiles created a possibility for a number of uses. Firstly, it allowed a great deal of real intercultural dialogue in relation to the understanding of how the different competences can be located in each degree. The experts, who came from different backgrounds in terms of their country of origin, cultural academic tradition and also of their different professional careers, arrived at an understanding of the main elements to be considered. Secondly, they were able to discuss how the different elements inter-related with each other and the level of centrality they occupied. Thirdly, in relation to the recognition of degrees, they found it of significant help to be able to see the weight of the core competences as against those located more in the periphery. Fourthly, each Subject-Area Group contrasted the meta-profile with a large and quite representative number of universities in the different countries in order to know which were the elements either missing or over-represented and how to improve the degrees in the various contexts. Further and very much to the point, these meta-profiles will serve as reference for the development of degree profiles in terms of the specificity 
of the region. Finally, it will be used to compare and contrast the regional perspective with the meta-profiles developed by other geographical areas, a bottom up way of reaching a global perspective.

\section{Consideration of future trends}

A concern for the relevance of higher education means a preoccupation with the present-day societal needs that it can help satisfy, but also a look into the input that degrees can have in shaping future societies and in anticipating social, economic, cultural and political changes. Designing degree profiles is basically an exercise in looking into the future. In the present context, degrees take time to be planned, developed and approved. Students need years to achieve their outcomes and mature in their learning and they are called to serve, to be prepared to act, innovate and to transform future societies and to meet future challenges. Profiles should look as much, if not more, to the future as to the present and this element of taking into account future trends in the specific field or fields where the degree is located, is a requirement for quality. Two things are then needed: to place an emphasis on the necessity of constant updating and to have a system to do so.

The Tuning project in Latin America tried to work on this task and initiated a methodology for introducing the analysis of future trends in the designing of profiles. In preparing to undertake this study, key contributions in the field of future and foresight studies were reviewed, revealing how well developed and sophisticated this foresight studies have become. Thus, methodology was adapted to the specific context placing an emphasis on some of the steps and opening the way for further analysis.

The first step looked at the state of the art and the most appropriate approaches available. Key contributions to future studies and strategic foresight fields recommend the study and assessment of the recent history and current situation before attempting to anticipate the future. This was carried out by the Tuning communities which debated current trends. They also discussed the contributions and limitations of the studies in foresight and strategic thinking and with a given methodology they prepared for in depth interviews. A generic text was adapted and the appropriate people general and field experts, leading professionals and academics, considered relevant for each of the different areas, were jointly selected to be interviewed.

The second step related to the general context of education. Many prospective studies have been undertaken in an effort to build future scenarios for higher education and to anticipate the challenges that higher 
education may face in the immediate future, as well as in the long run. ${ }^{38}$ These studies have underscored a wide array of driving forces that are more than likely to bring change to the state of affairs in higher education. They provide the general setting where the more specific study can rest. These studies focused on the necessary transformation of the traditional role of higher education institutions; they addressed educational policy and macro-tendencies, and sometimes institutional reform. They have proved to be important in analysing the impacts of societal changes. They open the road to the third step. This is moving beyond the general context of society and education into the each of the specific fields, analysing the changes in each of the areas at the country, regional and global level. It is at the level of the specific fields that the changes proved a great relevance and necessary to consider the translation of these challenges and emerging needs into curricular reform, and also into implementing them at the level of degrees.

The aim was to identify and draw conclusions for each subject area on the drivers for change present in society and the foreseen challenges over a period of twenty years. Following from this, a number of possible scenarios were developed and the implications for each of the specific scientific and professional areas were reflected upon. A fourth step was given by the consideration of the implications for the specific area of each of the scenarios, with the emergence of new professions or professional approaches or tendencies being developed. A very relevant aspect in the analysis was the focus on the new competences required by the general trends or by the specific context, scenarios and professions emerging in the future and how these factors can shape the future of the education in general and of degree profiles in particular.

The impact of future trends and drivers for change are of great significance in degree profile preparation. Diverse methodologies of consultation and scenario building are being developed further at some of the Tuning Communities. The nearly 500 interviews carried out with a selected

${ }^{38}$ Cf. Harry Anthony Patrinos and George Psacharopoulos, Education: Past, Present and Future Challenges. Policy Research Working Paper (Washington DC: World Bank, 2011), http://www-wds.worldbank.org/servlet/WDSContentServer/WDSP/IB/2011/03/29/00 0158349_20110329095336/Rendered/PDF/WPS5616.pdf; Martin Schlotter, Guido Schwerdt, and Ludger Woessman, The future of European education and training systems: key challenges and their implications, European Expert Network on Economics of Education, 2008,http://www.eenee.de/portal/page/portal/EENEEContent/_IMPORT_TELECENTRUM/ DOCS/EENEE_AR; Stéphan Vincent-Lacrin, "Building future scenarios for universities and higher education: an international approach," Policy Futures in Education 2, no. 2 (2004): 245-263. 
methodology in 15 areas in Latin America ${ }^{39}$ bring a wealth of material, but it is only an entry point into a more specialised study planned at the level of a specialised research groups which will deepen the perception of the impacts of future trends, challenges and drivers for change and transformation.

\section{The mark of the university where the degree is anchored}

Finally, there is another element to be taken into consideration in degree profiling. This is the university where the degree is anchored. One of the achievements in the post Bologna phase is that degrees have become an institutional venture, a fruit of collegiate activity in both design and delivery. At the present time, it is difficult to find a higher education institution without a mission and a vision that it proclaims to follow. This was not the case in many parts of the world before the 1990s.

Bringing in the individual university context adds the need to reflect on the processes of differentiation present among the world of higher education institutions. Thus, van Vught ${ }^{40}$ considers that the educational literature is clear about the desirability of diversity as one of the major factors associated with the positive performance of higher education systems. Based on previous literature, he summarises the arguments in favour of an increase in diversity as: (1) an important strategy to meet students' needs, offering access and opportunities to people from different backgrounds who require an educational environment more suited to their needs; (2) a way to favour social mobility by providing multiple forms and points of entry, transfer and exit allowing a system for the correction of errors of choice and providing for further opportunities for success; (3) a means to meet more adequately the diverse needs of employability; (4) an answer to serve the political needs of interest groups in society to have their own identity and legitimization; (5) a strategy to permit the important combination of elite and mass in higher education; (6) a means to attain high effectiveness due to the concentration and dedication to specific tasks; and (7) a context to experiment with innovation without having to implement innovation at all institutions and allowing for low risk in this experimentation.

39 Tuning América Latína, Cuarta reunión general: documento de trabajo (2012), 61-62, http://www.tuningal.org/es/publicaciones/doc_download/106-documento-de-trabajo-reunionde-bruselas

${ }^{40}$ Frans A. van Vught, "Mission diversity and reputation in higher education," Higher Education Policy 21, no. 1 (2008): 151-174. 
This diversity has been discussed and conceptualized in a model and further portrayed in the U-Map. ${ }^{41}$ It has also been developed into a more viable system of ranking - Multirank with institutional diversity at the heart of the system..$^{42}$ According to these instruments for analysis and higher education policy development, institutional variety can be seen to concentrate around a number of factors such as: regional orientation, educational needs, innovation or research dominant dimensions or international orientation.

If the usefulness and the potential impact of such tools were not clear, one proof would be the fact that an Australian version of the European university profiling tool has been developed and will be introduced soon in that country. ${ }^{43}$ The authors of the new tool also recognize that the results of attempting to use it in Australian universities proved that, contrary to expectations, there was significant diversity among institutions.

The identification and even the strategy to work towards a specific real or desired profile of a Higher Education Institution can be equated to a strategy of striving for quality, attempting to build on the institutional strengths as well as being a way to foster the realization of the university mission. The types of degree offered and their specific characteristics. Thus a university may choose, for example to have a high level of management of technologies as one of its special traits, other may want to have a component of social responsibility present in every profile as a distinctive element. Once the university mission is declared, this has a bearing on the degrees offered by the same university as a sign of quality, service and consistency with the mission.

\section{Conclusions}

A number of conclusions can be drawn. The first conclusion is that Degree Profiles are useful. They are useful for the learner since s/he is able to identify easily the set of competences and learning outcomes s/he will be required to achieve. It will provide an investment for future life, job opportunities, personal development and preparation to think, act, innovate and transform in a knowledge society, which is both plural and rapidly

${ }^{41}$ Frans A. van Vught et al., "U-Map: The European Classification of Higher Education Institutions.” Enschede: CHEPS, 2010, http://www.u-map.org/U-MAP_report.pdf.

${ }^{42}$ Frans A. van Vught and Frank Ziegele, eds., Multidimensional ranking: The design and development of U-Multirank (Dordrecht / Heidelberg / London / New York: Springer, 2012).

${ }^{43}$ Andrew Trounson, "Australia's new accountability tool," Inside Higher ED, February 13, 2013, http://www.insidehighered.com/news/2013/02/13/australia-adapts-european-uniontool-comparing-universities 
changing. Their usefulness relates also to the transparency that degree profiles provide for the different stakeholders. Learners will have a better chance of knowing in which Institution they wish to enrol and which educational experience to commit. Transparency is closely related to accountability. Once the profile is designed and presented, it is a commitment for the Institution to provide the processes leading to the attainment of what it portrays.

The second conclusion is that Degree Profiles are important as focal points to crystallise the many demands which come from different expectations and which would be otherwise difficult to name and to provide with a route map. In our present and still more in our future society, learners have and will have to prepare for jobs which, in some cases will need to be created for the first time. They will need to possess competences which are highly specialised and at the same time generic for rapidly changing contexts in a society which needs to be constantly re-imagined. Profiles are important to channel the thoughts and the innovative experiences which diversify and give options for the future.

The third conclusion is that the Degree Profiles are needed for quality in the context of competence-based, student centred learning. A clear profile serves as a meeting point for the institution which offers it, the staff who are responsible for the development of the educational environments and paths to be reached and the learner who will share the responsibility for seeing that the specific set of outcomes is attained. It is particularly the learner who needs to be aware of the results required to be able to choose, contribute and be sure to attain those results. This shared responsibility makes of the degree Profile a necessity which regulates and enlightens the target and the process. The need for degree profiles also comes from the level of mobility present in today's world. People experience growing demands for employment mobility all over the world. This means that large firms need complementary educational and experiential backgrounds that can be understood and easily read. It also means that institutions and individuals must increase their capacity to understand different cultures, systems and backgrounds and even more their outcomes.

With degrees more and more often achieved in a wide variety of countries and continents, it is especially important that the diverse processes and different learning experiences can be identified. The designed processes lead to the achievement of a set of desired learning outcomes that can be recognised anywhere in the world. This is provided that the degree has been designed upon a process of informed reflection and that the degree in question has been acknowledge as high-quality by relevant professional or national bodies. The work of recognition of prior learning would become impossible without well designed and accepted degree Profiles. 
The fourth conclusion is that Degree Profiles need to be complemented by a programme in which the educational experiences can underpin the development of the set of competences and learning outcomes, allowing for a variety of paths and environments, all within the framework of clear units of learning which facilitate the identification of the weight and the importance of each of the elements. It is the programme which makes it possible to verify and assure the consistency of the outcomes and the paths to achieve them.

The fifth conclusion is that degree profiles ought to follow a road map for their development. It is important to undertake consultation in respect of the social and professional needs so that the meta-profile contributes to the understanding of the subject area and the agreement on it within the region. Equally, future trends need to be taken into account in a context of rapid change. In the same way, the mission of the institution and the central nature of the degrees would, if appropriately carried out, give a dimension of consistency in relation to university mission as well as a level of diversity as between the institutions.

The last conclusion is that degree profiles are decisive for Higher Education due to the impact that they are called to have on society. They can display a significant level of relevance as they relate to social needs. They can prove a useful tool as they develop as an important element in the formation of a region, thus showing the capacity to foster a political dimension. Degree profiles are able to enhance the responsibility of citizens and can create cohorts of young people with deeper democratic culture, a culture of dialogue, of respect for the difference and of commitment to the creation of quality of life for all. This quality needs to be created particularly for the most vulnerable members in society: a quality measured by the capacity of empowerment and of making education an effective tool to transform societies.

\section{Bibliography}

Adelman, Clifford. The Bologna Process for U.S. eyes: re-learning higher education in the age of convergence. Washington, DC, 2009. http://www.ihep.org/assets/ files/EYESFINAL.pdf

Bergan, Sjur. Qualifications - Introduction to a concept. Strasbourg: Council of Europe Publishing, 2007.

Bologna Working Group on Qualifications Frameworks. A Framework for Qualifications of the European Higher Education Area. Copenhagen: Ministry of Science, Technology and Innovation, 2005. http://www.bologna-bergen2005. no/Docs/00-Main_doc/050218_QF_EHEA.pdf

- The Bologna Process independent assessment: The first decade of working on the European Higher Education Area, Vol. 1. 2010. http://ec.europa.eu/ 
education/higher-education/doc/bologna_process/independent_assessment_1_ detailed_rept.pdf

CHEPS, INCHER \& ECOTEC. The Bologna Process independent assessment: The first decade of working on the European Higher Education Area, Vol. 2. 2010. http://ec.europa.eu/education/higher-education/doc/bologna_process/ independent_assessment_2_cases_appendices.pdf

CLAR: Latin American reference credit. Bilbao: University of Deusto, 2013.

Crossley, John N., and Constant J. Mews, eds. Communities of Learning: Networks and the shaping of intellectual identity in Europe, 1100-1500. Turnhout: Brepols Publishers, 2011.

Eckert, Penelope. "Communities of Practice." In Encyclopedia of language and linguistics, edited by Keith Brown, 638-685. Amsterdam: Elsevier Ltd., 2006. http://www.sciencedirect.com/science/article/pii/B0080448542012761

González, Julia, and Robert Wagenaar, eds. Tuning educational structures in Europe: Final Report. Phase One. Bilbao: University of Deusto and University of Groningen, 2003.

Kehm, Barbara M. "Editorial." European Journal of Education. Special Issue: The Bologna Process revisited 47, no. 3 (2012): 343-347. doi: 10.1111/ j.1465-3435.2012.01529.x

Knight, Jane. "A conceptual framework for the regionalization of higher education in Asia: application to Asia." In Higher education regionalization in Asia Pacific: Implications for governance, citizenship and university transformation, edited by John N. Hawking, Ka Ho Mok, and Deane E. Neubauer, 17-36. London/New York: Plagrave Macmillan, 2012.

Kohler, Jürgen. "Quality assurance, accreditation, and recognition of qualifications as regulatory mechanisms in the European HEA." Higher Education in Europe 28, no 3 (2003): 317-330.

Lokhoff, Jenneke, Bas Wegewijs, Katja Durkin, Robert Wagenaar, Julia González, Ann Katherine Isaacs, Luigi F. Donà dalle Rose, and Mary Gobbi. A Tuning guide to formulating degree programme profiles. Bilbao, Groningen, The Hague: University of Deusto, 2010.

Lumina Foundation. The degree qualification profile. 2011. http://www. luminafoundation.org/publications/The_Degree_Qualifications_Profile.pdf

OECD. Tertiary Education for the Knowledge Society. Paris: OECD Publishing, 2008.

Patrinos, Harry Anthony and George Psacharopoulos, Education: Past, Present and Future Challenges. Policy Research Working Paper. (Washington DC: World Bank, 2011). http://www-wds.worldbank.org/servlet/WDSContentServer/ WDSP/IB/2011/03/29/000158349_20110329095336/Rendered/PDF/ WPS5616.pdf

Pedersen, Olaf. The First Universities - Studium Generale and the Origins of University Education in Europe. Cambridge: Cambridge University Press, 1997.

Pedraza Aboytes, Gustavo. ed. Higher Education in Latin America. Reflections and Perspectives in Chemistry. Bilbao: Universtiy of Deusto, in press. 
Petrova, Irina, Viktoriya Zaripova, Evgeniya Ishkina, Andrei Malikov, Irina Zakharova, Nikolai Kurmishev, Oleg Kuzenkov, and Viktor Varfolomeev. Tuning Russia. Reference points for the design and delivery of degree programmes in Information and Communication Technologies. Bilbao: University of Deusto, 2013.

Samardžić-Marković, Snežana. "A word from the Council of Europe's Director General for Democracy." In Reimagining democratic societies: A new era of personal and social responsibility, edited by Sjur Bergan, Ira Harkavy, and Hilligje van't Land, 7-8. Strasbourg: Council of Europe Publishing, 2013.

Schlotter, Martin, Guido Schwerdt, and Ludger Woessman. The future of European education and training systems: key challenges and their implications. European Expert Network on Economics of Education, 2008. http://www.eenee.de/portal/ page/portal/EENEEContent/_IMPORT_TELECENTRUM/DOCS/EENEE_AR

Serrano, Clara Tamayo. "El aporte cultural y educativo de la Baja Edad Media." Educación y Educadores 10, no. 2 (2007): 197-213.

Sin, Cristina. "Academic understandings of and responses to Bologna: a threecountry perspective." European Journal of Education. Special Issue: The Bologna Process revisited 47, no. 3 (2012): 392-404. doi: 10.1111/ j.1465-3435.2012.01533.x

Sorbonne Joint Declaration: Joint declaration on harmonisation of the architecture of the European higher education system. 1998, May 25. http://www.bolognaberlin2003.de/pdf/Sorbonne_declaration.pdf

Sursock, Andrée, and Hanne Smidt. Trends 2010: A decade of change in European Higher Education. European University Association: Brussels, 2010. http:// www.eua.be/publications/eua-reports-and-studies.aspx

The Berlin Communiqué: Realising the European Higher Education Area. 2003. http://www .ond.vlaanderen.be/hogeronderwijs/bologna/documents/MDC/ Berlin_Communique1.pdf

The Bologna Declaration of 19 June 1999: Joint declaration of the European Ministers of Education. 1999, June 19. http://www.bologna-berlin2003.de/pdf/ bologna_declaration.pdf

Trounson, Andrew. "Australia's new accountability tool," Inside Higher ED, February 13, 2013, http://www.insidehighered.com/news/2013/02/13/australiaadapts-european-union-tool-comparing-universities

Tünnermann Bernheim, Carlos, and Marilena de Souza Chaui. Challenges of the university in the knowledge society, five years after the World Conference on Higher Education. UNESCO Forum Occasional Papers Series. Paris: UNESCO, 2003.

Tuning Africa Civil Engineering Subject Area Group. Final Report "Tuning and Harmonization of Higher Education in Africa” Pilot Project. Civil Engineering. Bilbao: University of Deusto, in press.

Tuning América Latína. Cuarta reunión general: documento de trabajo .2012. http:// www.tuningal.org/es/publicaciones/doc_download/106-documento-de-trabajoreunion-de-bruselas 
Van Vught, Frans A. "Mission diversity and reputation in higher education." Higher Education Policy 21, no. 1 (2008): 151-174.

Van Vught, Frans A., and Frank Ziegele, eds., Multidimensional ranking: The design and development of U-Multirank. Dordrecht/Heidelberg/London/New York: Springer, 2012.

Van Vught, Frans A., Frans Kaiser, Jon File, Christiane Gaehtgens, Rolf Peter, and Don Westerheijden. "U-Map: The European Classification of Higher Education Institutions." Enschede: CHEPS, 2010. http://www.u-map.org/U-MAP_report.pdf

Veiga, Amélia. "Bologna 2010. The moment of truth?" European Journal of Education. Special Issue: The Bologna Process revisited 47, no. 3 (2012): 378391. doi: 10.1111/j.1465-3435.2012.01532.x

Vicent-Lancrin, Stéphan. "Building future scenarios for universities and higher education: an international approach." Policy Futures in Education 2, no. 2 (2004): 245-263. 